\title{
Análise do Ambiente Informacional no Processo de Patente Brasileiro
}

\section{Analysis of the Informational Environment in the Brazilian Patent Process}

\author{
Giuliano Carlo Rainatto*a; Orlando Roque Silva ${ }^{\mathrm{b}}$; Denis Gustavo Paschoal ${ }^{\mathrm{c}}$; Norberto Almeida Andrade ${ }^{\mathrm{b}}$; Fernando Silva ${ }^{\mathrm{d}}$
}

\author{
${ }^{a}$ Universidade Anhanguera de Guarulhos. SP, Brasil.

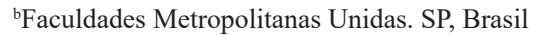 \\ 'Salford University, Programa de Pós-Graduação Stricto Sensu em Administração. Inglaterra. \\ ¿Faculdade Campo Limpo Paulista. SP, Brasil \\ *E-mail: giulianorainatto@yahoo.com.br
}

\begin{abstract}
Resumo
A patente é uma ferramenta importante para o inventor, pois concede a ele um monopólio temporário de exploração devido à novidade atingida durante as pesquisas para a invenção. Atualmente os inventores brasileiros têm 30 mil pedidos no INPI, que concede cerca de 900 pedidos por ano de patentes depositadas. Essa lacuna entre entrada e saída de patentes, ocorre muito por parte de um sistema lento e criado só para poder coexistir com outros modelos de proteção. A presente pesquisa teve o intuito de analisar o processo de patentes brasileiro, valendo-se da ótica da informação, observando se a mesma é responsável pela fuga de pedidos de patentes do Brasil para o exterior. Foi utilizada uma pesquisa quali-quantitativa, com questionário apresentado via web, e também um roteiro de entrevista semiestruturada, visando identificar o que os inventores percebiam no ambiente informacional do INPI. Foi possível identificar que existe um gap entre a percepção e a expectativa da informação vinda do INPI para os inventores, criando um ruído em todo o processo de patenteamento. As entrevistas efetuadas corroboram com o questionário quantitativo, pois mostraram o descontentamento tanto ao volume quanto à qualidade e à velocidade da informação apresentada pelo INPI. Esses dados são suficientes para mostrar que o processo de patentes brasileiro, na ótica da informação, é muito ruim, pois, após longos anos de espera, a expectativa do inventor é muito distante da percepção.
\end{abstract}

Palavras-chave: Patentes. Proteção Industrial. SERVQUA. Vantagem Competitiva.

\begin{abstract}
A patent is an important tool for the inventor as it gives him a temporary monopoly of exploitation due to the novelty achieved during research for the invention. Currently Brazilian inventors have 30,000 applications at the INPI, which grants about 900 patent applications per year filed. This gap between patent entry and exit occurs largely from a slow system designed just to coexist with other protection models. This research aimed to analyze the Brazilian patent process, using the information perspective, observing if it is responsible for the escape of patent applications from Brazil to abroad. A qualitative and quantitative research was used, with a questionnaire presented via the web, as well as a semi-structured interview script, aiming to identify what the inventors perceived in the informational environment of the INPI. It was possible to identify that there is a gap between the perception and expectation of the information coming from the INPI to the inventors, creating a noise throughout the patenting process. The interviews carried out corroborate the quantitative questionnaire, as they showed discontent regarding both the volume and the quality and speed of the information presented by the INPI. These data are sufficient to show that the Brazilian patent process, from an information point of view, is very bad, because after long years of waiting, the inventor's expectation is very far from perception.
\end{abstract}

Keywords: Patents. Industrial Protection. SERVQUAL. Competitive Advantage.

\section{Introdução}

Segundo a World Intellectual Property Organization (WIPO, 2017), atualmente o Brasil concede um total de novecentas cartas patentes de pedidos de inventores brasileiros, e esse número corresponde a apenas $3 \%$ do total de pedidos depositados anualmente no Instituto Nacional de Propriedade Intelectual (INPI). Porém, segundo Helpman (1993), existem três fatores que influenciam o processo decisório dos inventores sobre a tratativa do patenteamento: o custo, o tempo e a percepção informacional. Este último fator será o cerne do presente trabalho.

Segundo Taylor (1974), o problema central do consumo de um bem ou serviço é de que a informação ou a falta dela traz o consumidor para uma percepção de risco ou de incerteza, levando-o a pensar em um futuro próximo e suas consequências. Consoante Locander e Hermann (1979), pouco ainda se sabe sobre como o consumidor busca a informação a fim de reduzir o risco e a incerteza em suas operações, e o entendimento desses sentimentos traria benefícios não só para as empresas de marketing, mas também para agências governamentais e outros institutos que validassem a informação como uma ferramenta de escolha do consumidor.

A patente é um instituto de afirmação da invenção (BRASIL, 2017). Ela dá ao inventor oportunidade de exclusividade durante o período de exploração, inibindo o mercado da cópia e congratulando o criador pelos esforços e investimentos em pesquisa e desenvolvimento. A concessão 
da patente é um ato administrativo, tendo como intuito estimular a inovação tecnológica do país, ampliando suas divisas e qualificando seus inventores.

Contudo, órgãos governamentais podem ser uma dificuldade no caráter de informação. Hodiernamente, no Brasil, a média de tempo para a concessão de uma patente é de nove a onze anos, de acordo com Alves (2015), dependendo do volume de análises dos processos e das reanálises. Ainda conforme o tempo de pendência, há um impacto negativo no processo de conhecimento e evolução econômica, de modo que períodos mais longos de espera geram perdas maiores para seus inventores.

\section{Material e Métodos}

A metodologia para a realização da presente pesquisa lidou com dados qualitativos e quantitativos, e o instrumento usado para a coleta de dados foi o questionário adaptado do modelo SERVQUAL, publicado por Parasuraman et al. (1985).

Conforme descreve Gil (2008), as pesquisas podem se classificar quantos aos seus objetivos gerais em três tipos: exploratórias, que são pesquisas que buscam proporcionar o aumento da familiaridade com o problema, tornando-o mais explícito; descritivas, que são pesquisas cujos objetivos são descrever determinadas características de uma população e tentar relacionar as variáveis dispostas no problema; e explicativas: pesquisas que identificam fatores contribuintes para a ocorrência de fenômenos explicando o motivo destes. O modelo utilizado nesta pesquisa é o exploratório, por se adequar mais ao entendimento qualitativo do projeto.

Todos os dados do questionário foram compilados e analisados com o auxílio de uma técnica denominada análise de conteúdo. A análise de conteúdo foi desenvolvida em três etapas: pré-análise; exploração do material e tratamento de dados; inferência e interpretação (BARDIN, 2009). Pautou-se a amostra da pesquisa em inventores nacionais ou internacionais que obtiveram patentes concedidas primeiramente no Brasil e depois no exterior. Inicialmente, foram abordados inventores locais; depois, buscaramse pessoas indicadas por esses primeiros entrevistados (snowball). Utilizando ferramentas como o PatentScope, da WIPO, o EspaceNet, da European Patent Office (EPO), e o Google Patents, identificaram-se os sujeitos, classificando-os por terem patenteado no Brasil, primeiramente, e depois no exterior, independente da nacionalidade do inventor. Por se tratar de uma pesquisa fenomenológica, como descrito por Siani, Correa e Las Casas (2016) este tipo de estudo vem ganhando reconhecimento como uma abordagem de pesquisa qualitativa, aplicável ao estudo de fenômenos importantes de diferentes campos, incluindo o da Administração, tendo como o roteiro um dos procedimentos centrais para a pesquisa do ponto de vista de uma realidade social dos sujeitos.

Foram feitas entrevistas e coletaram-se dados sobre o fenômeno do patenteamento primeiro no Brasil e posteriormente em outros países, a fim de obter um processo melhor construído no ambiente informacional. As análises foram feitas em três etapas, de acordo com os métodos de análise de conteúdo Bardin (2009): pré-análise do material, quando é feita uma formulação dos objetivos, checam-se as dimensões e direções de análise, seguindo toda a estrutura de escolha de documentos e preparação de materiais, e também quando são feitos os recortes e categorização dos materiais; categorização, quando a separação da unidade de registro tem como descrição principal "Ausência de informação no processo de patentes", e os sub-registros do processo são "Velocidade da informação", "Qualidade da informação no processo informacional nos pedidos de patentes" e as "Dificuldades na obtenção de informação dos pedidos"; por fim, a exploração do documento, que se deu a partir da administração das técnicas de corpus, classificando e demonstrando em um display o volume de palavras utilizadas e suas associações com o tema relacionado.

Nesse sentido de um universo limitado, Bardin (2009, p. 123) afirma que "nem todo o material de análise é susceptível de dar lugar a uma amostragem, e, nesse caso, mais vale abstermo-nos e reduzir o próprio universo (e, portanto, o alcance da análise) se este for demasiado importante". Seguindo esse entendimento e valendo-se de um universo reduzido, fez-se o cruzamento das informações e dados recebidos com as teorias apresentadas para poder obter uma conclusão sobre os possíveis resultados que poderiam ser apresentados.

Para a produção de um conteúdo mais organizado e dinâmico, foi feita uma codificação formando unidades de registro (UR), a fim de formar uma análise estruturada da pesquisa. Durante essa pesquisa, houve uma categorização das palavras por três setores macro, como qualidade, velocidade e dificuldade de obtenção.

Schoroeder, Ferrari e Maestrelli (2009) indicam que na construção de conceitos são fundamentais tanto para o quadro teórico da pesquisa como para o tratamento, sendo as palavras componente importante para a interação da pesquisa com o leitor. Selltiz, Wrightsman e Cook (1987) por sua vez, mostram que o conceito é percebido através de acontecimentos presenciados e recomenda que os mesmos sejam definidos de maneira abstrata, dando-se o sentido geral do que se deve emitir na apresentação dos estudos.

Para possibilitar o entendimento adequado do texto, é importante a definição dos termos operacionais pesquisados, descrevendo-se, também, as categorias mais importantes da pesquisa:

- Disfunção: é o grau que se atribui à significância, que, no ponto de vista de um sujeito, expressa a preferência sobre um conjunto total de características, aderindo aos postos e mostrando preferência sobre um mesmo conjunto;

- Disfunção informacional 1: gap existente entre os fatores informacionais valorizados pelos clientes e os serviços percebidos;

- Disfunção informacional 2: gap existente entre a 
percepção do inventor e a percepção do serviço do INPI na ótica do agente de patentes, demonstrando a lacuna entre a operação e a invenção;

- Disfunção informacional 3: gap existente entre as percepções dos serviços pós-entrega da conclusão da análise das patentes, demonstrando a diferença da percepção informacional de cada agente;

- Patente: produto final, o qual está sendo estudado, que leva aos seus proprietários a vantagem competitiva e o monopólio temporário;

- Função competitiva: função de similaridade entre os fatores competitivos que são esperados pelos inventores (clientes) e os serviços oferecidos pelo INPI;

- intrínseca: categoria apresentada que trata da qualidade de um serviço, de maneira que as informações são apresentadas de forma a indicar a assertividade e a reputação dos dados (GERMANO; TAKAOKA, 2012);

- Acessibilidade: categoria que trata do acesso à informação do processo de concessão de patente apresentado (GERMANO; TAKAOKA, 2012);

- Contextual: categoria que retrata se o contexto apresentado é interessante, se tem valor agregado e se a informação é apropriada à necessidade do projeto (GERMANO; TAKAOKA, 2012);

- Representação: categoria que retrata sobre a interpretação, concisão e manipulação das informações recebidas, a fim de operacionalizar os dados recebidos em informações (GERMANO; TAKAOKA, 2012);

- SERVQUAL: ferramenta concebida por Parasuraman et al. (1985) e que compara a qualidade entregue e a qualidade esperada;

- Qualidade da informação: um dos alicerces para a sobrevivência e maior competitividade das organizações. Assim sendo, nos últimos anos, têm-se expandido os estudos e pesquisas sobre esse assunto, por exemplo, sobre como avaliar, medir e aprimorar a qualidade de informações, possibilitando às organizações utilizá-las e disponibilizá-las com maior eficiência e eficácia; tem sido o tema de pesquisa de vários autores (CALAZANS, 2008).

O universo populacional da pesquisa quantitativa foi composto por quinze inventores/clientes do INPI que entraram com pedidos de patente e proteção e passaram pelos processos de patenteamento. A pesquisa quantitativa também foi feita com dois agentes de patentes regulamentados no INPI, sendo eles os interlocutores entre os inventores e o INPI. Já o universo populacional da pesquisa qualitativa foi formado por quatro inventores/clientes que já possuem patentes registradas tanto no Brasil quanto no exterior.

A pesquisa foi enviada por e-mails para um grupo de inventores locais, e publicada na web para preenchimento por parte de pessoas que tenham patenteado alguma invenção. Dentre as perguntas eliminatórias, a colocação do número do processo ou da patente recebida foi fundamental para identificar eventuais outliers do processo. Todos os números foram checados, pois os documentos estão disponíveis no site do INPI ou via PatentScope (WIPO, 2017).

Foram conseguidas três amostras a partir da pesquisa da informação: Amostra 1 (quantitativa), referente ao grupo de inventores que patentearam ou solicitam patentes ao INPI;
Amostra 2 (quantitativa), referente aos agentes de patentes que solicitam e fazem os preenchimentos burocráticos solicitados pelos inventores; e Amostra 3 (qualitativa), referente aos inventores que patentearam no Brasil e no exterior e possuem conhecimentos nos dois processos.

Em todos os processos houveram clientes que responderam quanto à expectativa (Iexp), sendo um total de quinze respondentes, e também quanto à percepção (Iper), sendo um total dos mesmos 15 respondentes.

\section{Resultados e Discussão}

\subsection{Information Seeking Process (ISP)}

Entre as pesquisas acadêmicas feitas nas áreas de patentes, Information Seeking Process (ISP) de comportamento de clientes frente ao processo de compra de serviços tantos burocratizados quanto no mercado geral, os textos mostram diversas aprendizagens distintas que podem ser sintetizadas a fim de ampliar a coerência sobre o tema, o que aumenta a relevância da pesquisa, pois segundo Moura, Paes e Faria (2014), as patentes são importantes partes que o mercado tem para gerar riquezas e divisas ao país.

Os trabalhos de Locander e Hermann (1979) e de Kuhlthau (1991), por sua vez, trazem a expectativa do processo de busca da informação e a resposta do consumidor quando no entendimento sobre essa busca. Ambas as obras exploram as percepções de ansiedade e redução de risco na autoconfiança do processo de obtenção da informação.

A obra de Parasuraman et al. (1985) apresenta que um fator importante para assegurar uma boa qualidade em serviço é a obtenção de que as percepções dos consumidores excedam suas expectativas. Outros autores, como Germano e Takaoka (2012), indicam que as matrizes de apuração da qualidade da informação contribuem para que o consumidor se sinta amparado pelos serviços fornecidos.

Hylton (2016) transmite a informação da incerteza nas patentes e seus riscos para a evolução tecnológica e sua proteção ao inventor, e Troy e Werle (2008) apresentam dois tipos de incerteza no processo: a incerteza estratégica e a incerteza fundamental, que é amplamente discutida na academia.

Sintetizando as teorias em questão, pode-se entender que uma avaliação periódica dos anseios e expectativas dos consumidores consegue promover a melhora da satisfação em relação a um produto ou serviço (PALADINI, 1995). A presente pesquisa tem o intuito de sintetizar a coerência dessas áreas a fim de formar uma nova direção no processo de patentes e suas buscas para o consumidor do produto, analisando os gaps referentes às disfunções informacionais do sistema de patenteamento do INPI.

\subsubsection{Patentes}

As patentes são instrumentos fornecidos de maneira administrativa através do INPI, seguindo a Lei da Propriedade 
Intelectual (LPI), número 9279/96, que foi promulgada ainda no governo Fernando Henrique Cardoso a fim de manter a produção intelectual dentro do país, obedecendo a algumas normativas do Tratado de Madrid, assinado pelo Brasil em 9 de abril de 1978.

Apatente permite ao inventor se beneficiar economicamente de sua invenção. As patentes apresentam diversas vantagens de proteção ao seu detentor, como exclusividade e benefício econômico, porém a abordagem da incerteza no processo de concessão das patentes é um ponto muito importante a ser considerado durante a realização dos estudos sobre o patenteamento.

A incerteza no sistema de patentes é em grande parte inerente a duas variáveis: o grau de abstração do que está sendo protegido e o grau de fornecimento informativo que o pedido de proteção fornece. Essas duas variáveis não são controversas, pois uma patente pode ser devidamente abstrata, porém o escopo pode ser bastante detalhado e bem escrito, a ponto de merecer a proteção (HYLTON, 2016). Ainda de acordo com Hylton (2016), as premissas de incerteza variam a cada produto ou processo, cabendo outro ponto de preocupação, que é a avaliação do pedido de patente.

No Brasil, o processo de patentes tem um tempo a ser considerado. Há diversos passos para a obtenção da Carta Patente, aos quais se deve obedecer, e o processo, segundo Alves (2015), tinha como prazo, no ano de 2003, cerca de seis anos, passando para a média de oito anos em 2008 e, em 2011, para a média de onze anos, tudo isso devido à rápida defasagem tecnológica de apuração de resultado do Instituto Nacional de Propriedade Intelectual

\subsection{Information Seeking process e a incerteza de patentes}

Entre as pesquisas acadêmicas feitas nas áreas de patentes, Information Seeking Process (ISP) e de comportamento de clientes frente ao processo de compra de serviços tantos burocratizados quanto no mercado geral, os textos mostram diversas aprendizagens distintas que podem ser sintetizadas a fim de ampliar a coerência sobre o tema, o que aumenta a relevância da pesquisa, pois segundo Moura, Paes e Faria (2014), as patentes são importantes partes que o mercado tem para gerar riquezas e divisas ao país.

Os trabalhos de Locander e Hermann (1979) e de Kuhlthau (1991), por sua vez, trazem a expectativa do processo de busca da informação e a resposta do consumidor quando no entendimento sobre essa busca. Ambas as obras exploram as percepções de ansiedade e redução de risco na autoconfiança do processo de obtenção da informação.

O entendimento de busca da informação é importante porque gera ansiedade nos pesquisadores, podendo, muitas vezes, fazer com que a pesquisa falhe, o que pode gerar impaciência, baixa concentração e até depressão (NAVEED; AMEEN, 2016). Um processo de patentes pode levar anos, e as primeiras informações de andamento podem demorar até um ano para poder atingir os inventores, criando, além de ausência da informação, incerteza quanto ao sucesso do projeto.

\subsubsection{Incerteza Keynesiana e no processo de patentes}

Como apresentado por Keynes (1995), a incerteza é de que a tomada de decisão sem todas as informações adequadas disponíveis faz com que o tomador tenha de presumir uma série fatores antes de aguardar o resultado de sua decisão. A patente, como outros processos, depende de uma série de fatores que geram incerteza na apresentação do projeto junto ao INPI. Essa tomada de decisão de enviar um processo para o INPI avaliar deve ser tomada após um conjunto de informações serem recebidas de vários locais, uma busca prévia, para ver se já existe algo parecido, deve ser feita, o agente de patentes deve verificar se tem algo na sua base de clientes que seja próxima, e também uma pesquisa nas redes de informação deve ser feita a fim de fornecer o máximo de informações perante ao depósito no INPI.

Outros autores, como Hylton (2016), transmitem a informação da incerteza nas patentes e seus riscos para a evolução tecnológica e sua proteção ao inventor. Troy e Werle (2008), por sua vez, mostram dois tipos de incerteza no processo: a incerteza estratégica e a incerteza fundamental, amplamente discutida na academia.

$\mathrm{Na}$ racionalidade limitada, definida por Simon (1955), nenhum tomador de decisão define um processo de maneira a ter todas as informações frente ao processo pesquisado antes de a decisão ser efetivada. Esse conceito demonstra a importância da informação no processo de patentes para minimizar os riscos e custos desnecessários ao apresentar a patente ao INPI.

\subsection{Percepção do cliente (Patenteador)}

Alguns conceitos do marketing são relevantes no momento de sintetizar e comparar, na visão do inventor, todos esses passos. Pode-se utilizar para isso, por exemplo, a Transaction Utility Theory (TUT), que deriva da Prospect Theory, de Kahneman e Tversky (1999). A TUT, descrita por Thaler (1982), mostra que o comportamento do consumidor não depende apenas do preço percebido pelos produtos ou serviços, e sim de uma convergência entre o preço de venda e o preço que o consumidor consegue perceber do serviço proposto. O conceito concluso por Thaler (1982) de que o ponto de satisfação está em quem está mais feliz com a transação e de que a busca do consumidor pela vantagem na compra o faz trilhar tanto o caminho da busca pela informação (preços e locais) quanto pelo preço e custo percebido pelo produto ou serviço ofertado.

Existem dois importantes modelos de consumidores e seus processos de aquisição de um serviço ou produto, como Kahneman e Tversky (1999) propõe em suas pesquisas. O primeiro sistema é intuitivo, emocional e faz reacionar automaticamente para tomar as decisões sem pensar em nenhum segundo; o outro sistema é considerado lento, uma 
vez que o consumidor analisa as situações e circunstâncias antes da tomada de decisão.

Na proposta de patenteamento e a percepção informacional, é possível visualizar que a teoria apresentada se faz válida no momento de entender que o preço para patentear no Brasil pode ser caro - na visão do inventor -, frente a um serviço sem o tempo adequado e sem as informações mínimas necessárias ofertadas pelo INPI. Além disso, o processo deve ser de definição lenta porque cada informação deve ser analisada com propriedade com vistas de garantir os direitos dos consumidores do serviço após as concessões.

O modelo de lacunas (gaps) foi desenvolvido por Zeithaml, Berry e Parasuraman (1985) e teve o intuito de identificar inconsistências nas percepções e expectativas no desempenho dos serviços, auxiliando na orientação das pessoas sobre como gerir a qualidade dentro de seus negócios de acordo com cada gap. A Figura 1, apresenta uma parte superior em que estão as expectativas e necessidades dos clientes; a parte inferior apresenta os fenômenos do prestador de serviço; e, por último, o cliente recebe o serviço e tem a percepção sobre todo o componente solicitado, atribuindo uma qualidade ao processo de solução técnica recebida.

Figura 1 - Modelo de qualidade de serviço

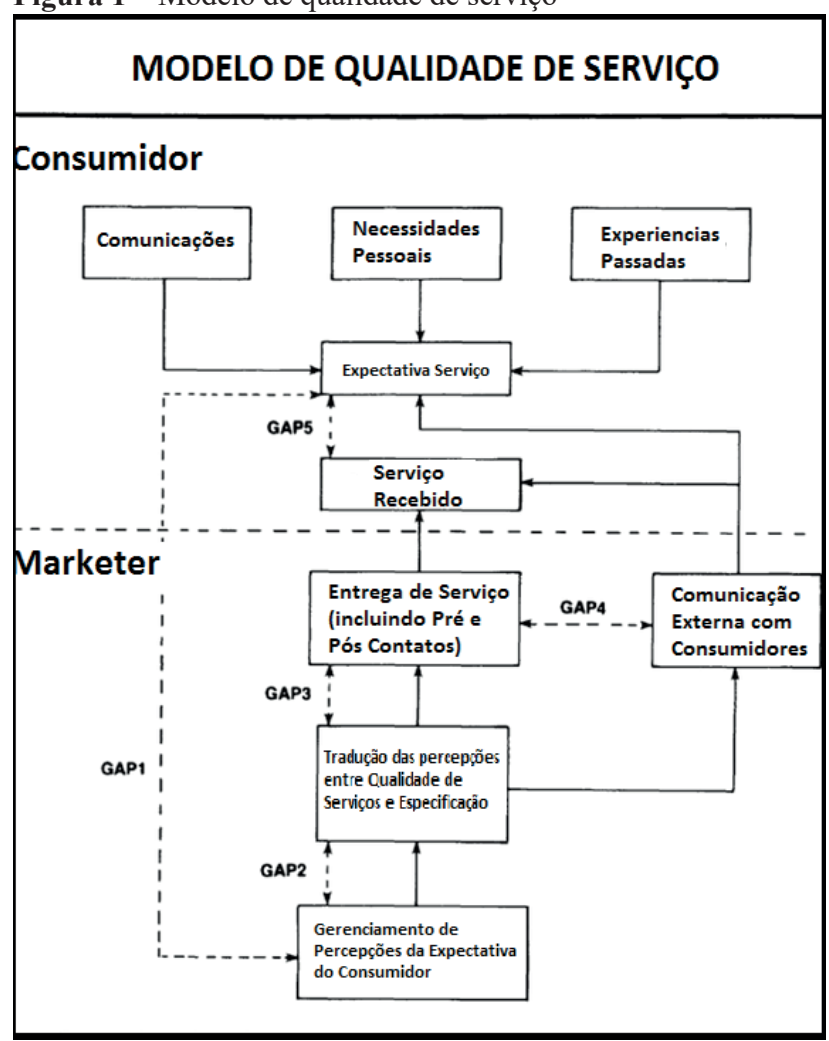

Fonte: Adaptado de Parasuraman et al. (1985)

O modelo proposto, Figura 2, demonstra o fluxo da informação, a absorção da percepção e a geração da expectativa no processo. Ao gerar um produto, o inventor tem uma expectativa da informação vinda do agente de patentes, com relatórios frequentes em busca do objetivo, que é a Carta Patente. Ao receber as necessidades do inventor, o agente de patentes fornece ao inventor um feedback de como funciona o processo e toda sua percepção do ambiente informacional do INPI.

Figura 2 - Processo da informação no INPI

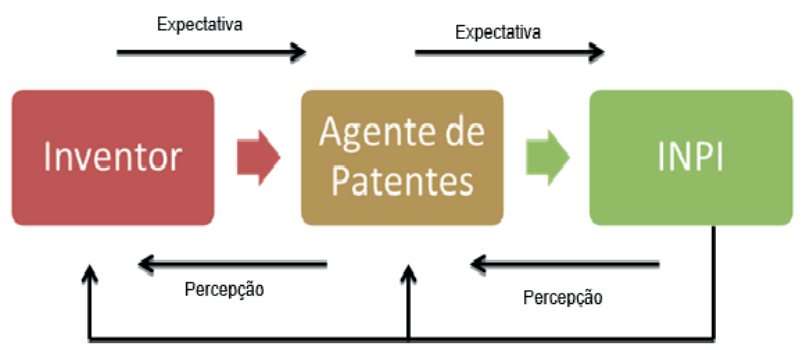

Fonte: Os autores.

$\mathrm{O}$ agente de patentes processa as necessidades dos clientes e entrega todo o processo para o INPI poder processá-lo em prol da realização do objetivo dos clientes, porém o INPI fornece informações esparsas e irrelevantes durante o prazo de análise do pedido. O momento em que a informação passa a ser importante para o inventor é após o exame técnico do pedido, pois nesse momento a relevância do feedback é alta, tratando-se do exame realizado no pedido.

"Qualidade é um elusivo e indistinto constructo", escreveram Zeithaml, Berry e Parasuraman (1985), sendo a qualidade de um serviço um constructo indispensável para a evolução de um negócio. Como descrito no artigo, quando um consumidor está prestes a adquirir um item, ele costuma julgar estilo, durabilidade, cor, etiqueta, sensação, pacote e caimento. Contudo, quando o consumidor está captando serviços, existem menos itens tangíveis.

A qualidade é uma comparação entre expectativa e performance, sendo o mesmo percebido entre as diferenças do que o consumidor espera (expectativa) contra o que ele mesmo encontrou no serviço oferecido. Há quem defina a qualidade como uma conformidade com as necessidades (GARVIN, 1992), fazer correto da primeira vez (CROSBY, 1979), porém, quando se discorre sobre informação, não se verifica somente como ela é apresentada é somente como a mesma nos é apresentada e sim de que maneira.

\subsection{Matriz da qualidade da informação}

Segundo Madnick et al. (2009) ainda que não se tenha obtido um consenso sobre a distinção entre as qualidades de informação e de dados, pode-se valer-se da qualidade dos dados para se referir de valores técnicos empreendidos. De acordo com Kahn e Strong (1998) a informação de qualidade é aquela que atende às especificações ou aos requisitos necessários para atingir a expectativa dos usuários. A matriz de qualidade da informação (Quadro 1) visa sintetizar dados para orientar se a informação apresentada está de acordo com a expectativa do usuário frente a um serviço ou produto, agregando um caráter técnico às necessidades diárias de informação. 
Quadro 1 - Matriz de qualidade

\begin{tabular}{|c|c|}
\hline \multicolumn{2}{|c|}{ Categoria - Intrínseca } \\
\hline Acuracidade & Nível de precisão da informação recebida \\
\hline Objetividade & Nível de objetividade da informação \\
recebida
\end{tabular}

Fonte: Germano e Takaoka (2012)

O modelo de Zeithaml, Berry e Parasuraman (1985) descreve algumas dimensões na qualidade de serviços e suas implicações para o futuro, abordando uma série de fatores importantes para o processo de conhecimento da qualidade. Dentre as proposições do estudo, uma delas descreve o espaço entre as lacunas específicas e necessárias para a expectativa versus a percepção e como isso pode afetar a qualidade, do ponto de vista do consumidor. Sendo esse espaço em branco o que está sendo pesquisado neste trabalho, essa percepção de qualidade informacional no processo nacional comparado com a expectativa do consumidor na obtenção dos serviços.

$\mathrm{O}$ Quadro de medianas (Quadro 2) foi obtida frente às 16 questões do questionário - adaptado do SERVQUAL - aplicado, conforme o modelo de qualidade de serviço, e tabulado frente ao agente de patentes com sua expectativa e sua percepção e dos inventores quanto a sua expectativa e, também, percepção.
Quadro 2 - Medianas

\begin{tabular}{|c|c|c|c|}
\hline & Média & $\begin{array}{c}\text { Desvio } \\
\text { Padrão }\end{array}$ & Mediana \\
\hline Expectativa do cliente & 4,37 & 0,8 & 5 \\
\hline GAP1 & & & \\
\hline Percepção do cliente & 2,81 & 0,65 & 3 \\
\hline Expectativa do inventor & 4,37 & 0,8 & 5 \\
\hline GAP 2 & & & 3 \\
\hline $\begin{array}{c}\text { Percepção do agente de } \\
\text { patentes }\end{array}$ & 2,87 & 0,71 & 3 \\
\hline $\begin{array}{c}\text { Percepção do agente de } \\
\text { patentes }\end{array}$ & 2,87 & 0,71 & 3 \\
\hline GAP 3 & 2,81 & 0,65 & 3 \\
\hline $\begin{array}{c}\text { Percepção dos inventores- } \\
\text { clientes }\end{array}$ & & & \\
\hline
\end{tabular}

Fonte: Dados da pesquisa.

\subsection{Análise dos resultados quantitativos}

No teste de Aderência da amostra do gap 1, em que se analisou a expectativa do inventor (cliente) versus a percepção dele (disfunção informacional 1), os resultados do teste do Qui-quadrado - usando os dados compilados na tabela 1 e demonstrando um nível de significância 0,05 - têm distribuição diferente, sendo que, em média, as respostas para expectativa e percepção foram de 4,3 e 2,8, respectivamente. Pelo teste de Mann-Whitney, pode-se afirmar que a diferença das respostas é estatisticamente significativa ( $\mathrm{p}$-valor $<0,001$ ) e, portanto, a informação percebida difere do esperado pelos clientes. Os resultados do teste Qui-quadrado e do teste $\mathrm{G}$ indicam que não há dependência entre as respostas dos clientes, ou seja, o valor da mediana da resposta em relação à expectativa independe da reposta da percepção.

Nos testes apresentados, o entendimento do consumidor sobre ter uma expectativa maior que a percepção vem ao encontro com o que Kuhlthau (1991), que apresenta em que, na busca pela informação, o cliente tenta reduzir os riscos e as incertezas do processo de compra ou aquisição. Vê-se que, caso o cliente possuísse mais informação sobre o processo e suas dinâmicas e fosse informado sobre a espera, é provável que ele não escolheria o sistema nacional para patentear seus inventos, e sim iria a outros países, como abordado na pesquisa qualitativa apresentada.

Com a obtenção dessa diferença grande entre a expectativa e a percepção dos clientes, a incerteza processual, como apresentado por Hylton (2016), faz-se presente porque uma informação qualificada reduziria muito a diferença dessa lacuna, mas, por ora, apresenta aos inventores um processo demorado e sem as informações precisas.

Quadro 3 - Resultados dos testes do gap 1

\begin{tabular}{|c|c|l|}
\hline Teste & Estatística do teste & p-valor \\
\hline Mann-Whitney & 23 & $<0,001$ \\
\hline Qui-Quadrado & 2,59 & 0,99 \\
\hline G & 2,67 & 0,99 \\
\hline
\end{tabular}

Fonte: Dados da pesquisa. 
Figura 3 - Distribuição das respostas dos clientes

Expectativa x Percepção

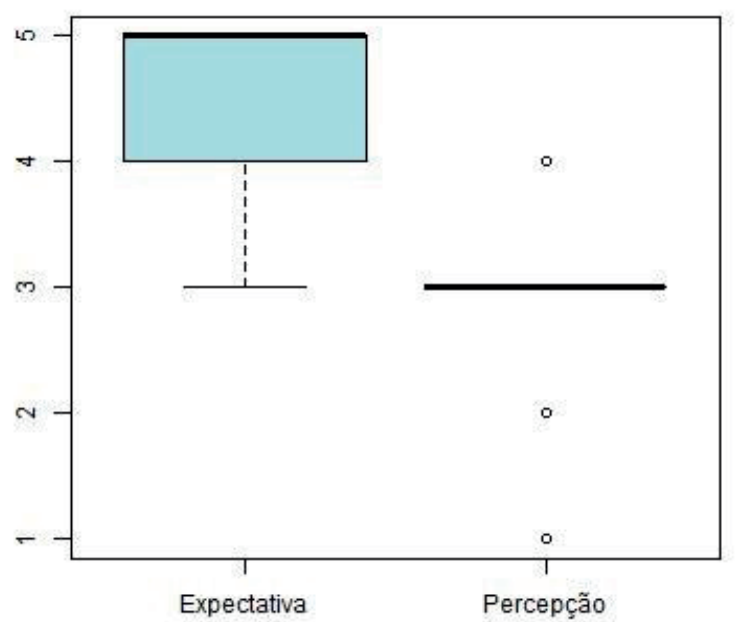

Fonte: Os autores.

Pelos resultados obtidos, não se rejeita a hipótese $\mathrm{Hb} 0$, pois existe discrepância entre aquilo que o cliente espera e o que é percebido no ambiente informacional.

Hipótese Hc0: o gap 2 falha na expectativa do inventor frente às demandas de pedidos de patentes e a percepção apresentada pelos agentes de patentes

No teste de Aderência das amostras do gap 2, analisouse a expectativa do inventor versus a percepção do agente de patentes (disfunção informacional 2), pois apresentam-se diferenças entre a expectativa da informação pelo inventor frente ao que os agentes de patentes percebem do INPI. Usando o Quadro 2, os testes demonstraram que a expectativa do inventor se mostra alta em relação à percepção do agente de patentes, pois a maioria das repostas estão entre 4 e 5, enquanto as respostas dos agentes estão entre 2 e 3. Essa diferença é significativa, de acordo com o teste de Mann-Whitney ( $p$-valor $<0,001)$. Pelo teste Qui-quadrado, tem-se que as respostas dos inventores e dos agentes são independentes. Tal resultado também é confirmado pelo teste $\mathrm{G}$ e, portanto, a expectativa do inventor independe da percepção do agente de patente.

Quadro 4 - Resultados dos testes do gap 2

\begin{tabular}{|c|c|c|}
\hline Teste & Estatística do teste & p-valor \\
\hline Mann-Whitney & 27 & $<0,001$ \\
\hline Qui-Quadrado & 3,83 & 0,99 \\
\hline G & 3,84 & 0,99 \\
\hline
\end{tabular}

Fonte: Os autores.
Figura 4 - Expectativa do inventor x Percepção do agente de patentes

Expectativa do inventor $x$ Percepção do agente de patentes

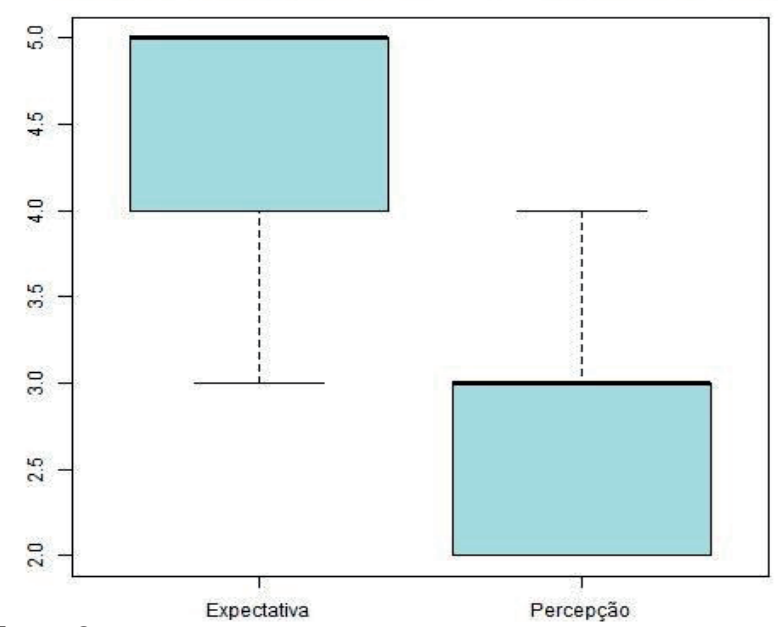

Fonte: Os autores.

Kahneman e Tversky (1999) e por Thaler (1982) trazem o entendimento de que os valores de diferenciação para a aquisição de um produto ou serviço são pautados em uma convergência entre as percepções e, pelo entendimento, no Brasil a patente é cara e com serviços informacionais ruins, não apresentando convergência para que o consumidor possa selecionar o INPI como um local adequado para consumir um serviço. Ainda de acordo com Thaler (1982), a busca pela satisfação no consumo faz o cliente trilhar a busca pela informação adequada, tanto quanto pelo preço quanto pelo custo percebido. Porém os modelos de consumidores são diferentes dos tratados na teoria, em que muitos dos inventores buscam apenas o resultado final (Carta Patente).

Pelos resultados obtidos, confirma-se a hipótese $\mathrm{Hc} 0$, pois existe uma falha entre a expectativa da informação do inventor e na percepção do agente.

Hipótese Hd0: o gap 3 acontece no retorno da informação vinda do INPI, no momento crucial da reivindicação, quando as percepções do agente de patentes e do inventor convergem. Existe uma falha na percepção do agente frente à percepção do inventor, sendo a percepção do agente a maior mediana.

A última hipótese é apresentada no retorno da INPI das informações apresentadas, pois, em um período de análise do pedido de patente, as informações percebidas pelo inventor e pelo agente de patentes convergem entre si. Nesse momento, as percepções da informação recebida são distintas, de modo que o inventor se interessa pelo produto final e o agente se interessa pela forma como se pode dar continuidade ao projeto.

A mediana das respostas tanto dos agentes de patente quanto dos inventores é 3, apesar de as respostas dos agentes terem variado mais. Pelo teste de Mann-Whitney, não há diferença significativa entre a percepção dos agentes de patente e dos inventores-clientes. O teste Qui-quadrado, assim como o teste $\mathrm{G}$, indica que as repostas dos agentes de patente e dos inventores-clientes são independentes; assim, não há associação entre as percepções de ambos. 
Quadro 5 - Resultados dos testes do gap 3

\begin{tabular}{|c|c|c|}
\hline Teste & Estatística do Teste & p-valor \\
\hline Mann-Whitney & 127,5 & 1 \\
\hline Qui-Quadrado & 1,29 & 1 \\
\hline G & 1,30 & 1 \\
\hline
\end{tabular}

Fonte: Os autores.

Pelos resultados obtidos, rejeita-se a hipótese Hd0, pois as medianas e as percepções são iguais: o agente de patentes não tem uma mediana maior que a dos inventores da informação recebida do INPI após o retorno do processo.

Durante as entrevistas, buscou-se evidenciar o que os consumidores de serviços do INPI entendem por percepção versus expectativa da informação atribuída pelo órgão. Para isso, foram feitos os seguintes questionamentos: qual a disfunção observada?; qual dos gaps tem a maior mediana?; qual a mediana da disfunção informacional (gap 1)?; qual a mediana da disfunção competitiva (gap 2)?; qual a mediana da disfunção informacional (gap 3)?

Figura 5 - Distribuição das repostas quanto à percepção

Agente de patente $\mathrm{x}$ Inventores-clientes

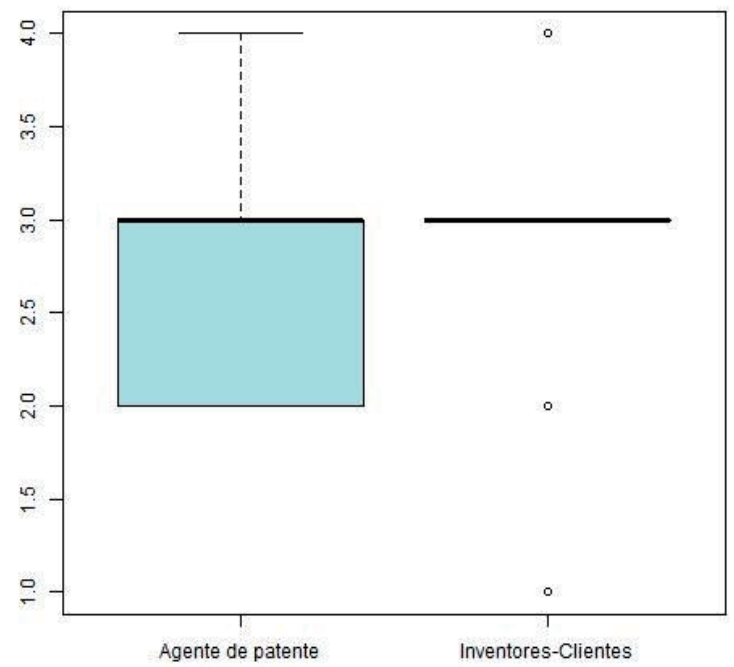

Fonte: Os autores.

Visando atender aos requisitos das questões, a pesquisa testou as seguintes hipóteses: Ha1 - Os gaps de menor mediana são o 1 e o 2; Hb1 - O gap 1 falha na percepção da expectativa do cliente em relação à qualidade da informação percebida, que é baixa, isto é, há uma diferença entre o serviço esperado e o percebido; Hc1 - o gap 2 falha na expectativa do inventor frente às demandas de pedidos de patentes e a percepção apresentada pelos agentes de patentes; Hd1 - o gap 3 acontece no retorno da informação vinda do INPI no momento crucial da reivindicação, quando as percepções do agente de patentes e do inventor se convergem; existe uma falha na percepção do agente frente à percepção do inventor, sendo a percepção do agente a maior mediana.

$\mathrm{Na}$ metodologia aplicada, apresenta-se um modelo de pesquisa quali-quantitativo, com a distribuição de um questionário via Web para inventores que já fizeram uso do sistema de concessão de patentes brasileiro, com obrigatoriedade de colocar seus números de processos para checagem, enviados através de dois agentes de patentes conhecidos do autor. A pesquisa qualitativa foi realizada com quatro inventores de conhecimento do inventor que já fizeram uso do sistema internacional de patentes e que puderam apresentar suas percepções do cenário nacional e do cenário internacional.

\subsection{Análise dos resultados qualitativos}

Após transcrever as entrevistas efetuadas com os quatro inventores que tiveram a experiência de seguir processo de patenteamento no Brasil e no exterior, conseguiu-se tabular uma série de unidades de registro simples a fim de identificar uma percepção do ambiente informacional do INPI. As Unidades de Registro foram divididas em subcategorias "Qualidade", "Velocidade" e "Dificuldade" — e visaram identificar a experiência nos dois ambientes, a fim de corroborar com a pesquisa quantitativa, como demonstrada a compilação no Quadro resumo dos resultados do teste do gap 3.

O Quadro 6 apresenta dados suficientes para corroborar o interesse do inventor em patentear no exterior primariamente, e depois trazer o processo para o Brasil via protocolo das patentes (PCT), fazendo com que o processo seja mais ágil e com um nível de informação e segurança mais adequado.

Quadro 6 - Quadro Resumo

\begin{tabular}{|c|c|c|c|c|}
\hline Atributos & Entrevista \#1 & Entrevista \#2 & Entrevista \#3 & Entrevista \#4 \\
\hline \multicolumn{5}{|c|}{ Qualidade } \\
\hline Q.1 - Objetivo & $\begin{array}{l}\text { Informação objetiva } \\
\text { até demais, dificulta o } \\
\text { entendimento }\end{array}$ & Informações são boas & $\begin{array}{c}\text { Informação sempre } \\
\text { objetiva }\end{array}$ & $\mathrm{N} / \mathrm{A}$ \\
\hline Q.2 - Amplo & $\begin{array}{l}\text { Informações vazias e sem } \\
\text { propósito }\end{array}$ & $\begin{array}{l}\text { Confusos e fora de } \\
\text { contexto }\end{array}$ & $\begin{array}{l}\text { Geralmente muita coisa } \\
\text { Irrelevante }\end{array}$ & $\mathrm{N} / \mathrm{A}$ \\
\hline Q.3 - Funcional & $\begin{array}{l}\text { Não tem nada a ver com o } \\
\text { produto }\end{array}$ & $\begin{array}{c}\text { Compararam com patentes } \\
\text { sem relevância }\end{array}$ & $\begin{array}{l}\text { Sempre vem mais } \\
\text { informação do que se } \\
\text { precisa }\end{array}$ & $\mathrm{N} / \mathrm{A}$ \\
\hline Q.4 - Assertivo & Cumprem protocolo & N/A & Eles mandam tudo junto & N/A \\
\hline Q.5 - Simples & $\mathrm{N} / \mathrm{A}$ & N/A & $\begin{array}{l}\text { Escrito de maneira que } \\
\text { dificulta a interpretação }\end{array}$ & $\mathrm{N} / \mathrm{A}$ \\
\hline
\end{tabular}




\begin{tabular}{|c|c|c|c|c|}
\hline \multicolumn{5}{|c|}{ Velocidade } \\
\hline V.1 - Lento & $\begin{array}{l}\text { Levou [sic] } 9 \text { anos as } \\
\text { primeiras notícias }\end{array}$ & $\begin{array}{c}\text { Foram } 8 \text { anos até a } \\
\text { chegada da informação }\end{array}$ & $\begin{array}{l}\text { Demoram uma } \\
\text { quantidade absurda de } \\
\text { tempo para devolver }\end{array}$ & $\begin{array}{c}\text { Pois em } 4 \text { anos só paguei } 4 \\
\text { anuidades }\end{array}$ \\
\hline V.2 - Rápido & \begin{tabular}{|l|} 
Vou pesquisar um país com \\
o andamento mais rápido \\
\end{tabular} & $\begin{array}{c}\text { Não temos ideia do } \\
\text { andamento do processo }\end{array}$ & N/A & $\begin{array}{c}\text { Imagina, em } 4 \text { anos nada } \\
\text { aconteceu }\end{array}$ \\
\hline V.3 - Ágil & N/A & N/A & N/A & $\begin{array}{l}\text { Optei em inverter o } \\
\text { caminho }\end{array}$ \\
\hline V.4 - Conciso & $\begin{array}{l}\text { Somos um monte de } \\
\text { palhaços por receber essas } \\
\text { informações em } 9 \text { anos }\end{array}$ & N/A & N/A & N/A \\
\hline \multicolumn{5}{|c|}{ Dificuldades } \\
\hline D. 1 - Confusa & Agentes despreparados & Fora de contexto & $\begin{array}{c}\text { Dá trabalho descobrir o } \\
\text { que se tem que fazer }\end{array}$ & N/A \\
\hline D. 2 - Posição & Demora 9 anos & $\begin{array}{c}\text { Levou } 8 \text { anos até a } \\
\text { chegada da informação }\end{array}$ & Demora... & $\begin{array}{c}\text { Esperar por } 4 \text { a } 5 \text { anos } \\
\text { por uma análise e optei } \\
\text { em agilizar o processo em } \\
\text { outro país }\end{array}$ \\
\hline $\begin{array}{c}\text { D.3 - } \\
\text { Andamento }\end{array}$ & & $\begin{array}{l}\text { Em comparação nos EUA } \\
\text { aonde tenho um pedido } \\
\text { que fiz há } 12 \text { meses já ter } \\
\text { sido avaliado }\end{array}$ & $\begin{array}{l}\text { Nos outros sistemas nunca } \\
\text { passou de } 4 \text { anos }\end{array}$ & $\begin{array}{c}\text { Foram } 4 \text { anos que paguei } 4 \\
\text { anuidades }\end{array}$ \\
\hline
\end{tabular}

Fonte: Os autores.

As unidades de registro extraídas das entrevistas corroboram com as pesquisas qualitativas apresentadas, demonstrando a dificuldade no nível informacional e também nos níveis gerais de patenteamento.

\section{Conclusão}

Esta pesquisa buscou analisar o ambiente informacional do processo de patente brasileiro através de uma pesquisa quantitativa que demonstrou as diferenças entre a expectativa e a percepção da informação que o cliente/inventor tem durante o processo de patenteamento. Valeu-se, para tanto, de autores conceituados nas áreas de ISP, incerteza, patentes e das teorias de transação que abordam as expectativas e mitigações de risco na busca pela informação.

A pesquisa conseguiu atingir os objetivos a ponto de identificar gaps informacionais entre a percepção e a expectativa, que podem impactar no processo de escolha do local de patenteamento, evidenciando que a informação esperada é diferente da informação percebida. Conseguiuse aplicar os questionários para os agentes de patentes para entender como está o ambiente informacional pelo ponto de vista desse profissional tão importante no processo de patenteamento. Os inventores foram entrevistados de maneira quantitativa, de maneira que se pôde evidenciar os gaps de forma numérica. Também foi feito uso da pesquisa qualitativa para poder corroborar com a conclusão de que existe, sim, diferença entre os processos de patente feitos no exterior e os feitos no Brasil.

No tocante da pergunta que norteou a pesquisa, pôde-se identificar que a informação somente não é responsável pela migração do processo para o exterior, mas é um dos fatores, pois os processos feitos no exterior têm muito mais informação e muito mais agilidade quando comparado ao sistema de patentes brasileiro. Durante as entrevistas, conseguiu-se extrair a informação de que os inventores que migraram para o processo de patenteamento em outro país obtiveram as patentes em um prazo muito menor do que se tivessem seguido os trâmites no Brasil através do PCT, conseguindo a patente no país estrangeiro de forma muito mais rápida do que pelas vias brasileiras.

Durante a pesquisa, algumas limitações foram encontradas, pois nem todos os entrevistados quiseram expor suas patentes, mesmo elas sendo apresentadas na Internet via PatentScope ou INPI. Existe também uma subjetividade ao analisar somente a informação vinda do INPI: muitas vezes, os entrevistados acabavam colocando toda sua angústia com a demora no retorno de informações por parte do INPI e o custo do patenteamento, de forma que foi necessária a interrupção das entrevistas por várias vezes a fim de corrigir o curso da mesma.

Por fim, a pesquisa leva à recomendação de que, para estudos futuros, seja feita uma análise do movimento migratório das patentes de países de terceira economia para países de primeira economia, retornando, posteriormente, aos países de origem, via PCT.

\section{Referências}

ALVES, M.R. País demora 11 anos para aprovar patentes. $O$ Estado de S. Paulo, 24 maio, 2015.

BARDIN, L. Análise de conteúdo. Lisboa: Edições 70, 2009.

BRASIL, DIRPRA. Manual para depositantes de patentes. Rio de Janeiro, 2017.

CALAZANS, A.T.S. Qualidade da informação: conceitos e aplicações. Transinformação, v.20, n.1, p. 29-45, 2008.

CROSBY, P.B. Quality is free: the art of making quality certain. Nova York: New American Library, 1979. 
GARVIN, D.A. Gerenciando a qualidade: a visão estratégica e competitiva. Rio de Janeiro: Qualitymark, 1992.

GERMANO, E.C.; TAKAOKA, H. Uma análise das dimensões da qualidade de dados em projetos de dados governamentais abertos. CONSAD. Disponível em: $<$ http://consadnacional.org. br/wp-content/uploads/2013/05/138-UMA-AN\%C3\%81LISEDAS-DIMENS\%C3\%95ES-DA-QUALIDADE-DE-DADOSEM-PROJETOS-DE-DADOS-GOVERNAMENTAISABERTOS.pdf>. Acesso em: 19 abr. 2019.

GIL, A.C. Métodos e técnicas de pesquisa social. São Paulo: Atlas, 2008.

HELPMAN, E. Innovation, imitation and intelectual property rights. Econometrica, v.61, n.6, p.1247-1280, 1993.

HYLTON, K.N. Patent uncertainty: toward a framework with applications. Boston: Boston University Law Review, 2016.

KAHN, B.K.; STRONG, D.M. Product and service performance model for information quality: an update. In: PROCEEDINGS OF THE 1998 CONFERENCE ON INFORMATION QUALITY. 1998, Cambridge, 1998

KAHNEMAN, D.; TVERSKY, A. Prospect theory: an analysis of decision under risk. Econometrica, n.49, p.263-291, 1999.

KEYNES, J.M. The state of long-term expectation. In: ESTRIN, S.; MARIN, A. Essential readings in economics. London: Palgrave, 1995.

KUHLTHAU, C.C. Inside the search process: information seeking from the user's perspective. J. Am. Soc. Inform. Scie., p.361-371, 1991.

LOCANDER, W.B; HERMANN, P.W. The effect of selfconfidence and anxiety on information seeking in consumer risk reduction. JMR, p.268-274. 1979.

MADNICK, S. et al. Overview and framework for data and information quality research. Data Inform. 2009. Disponível em: $<$ http://doi.acm.org/10.1145.1515693.1516680>. Acesso em: 14 abr. 2019.
MOURA, F.R.; PAES, N.L.; FARIAS, T. A. O impacto do tempo de pendência das patentes na trajetória de crescimento: uma análise com base no modelo Schumpeteriano de crescimento endógeno com avanço de qualidade. Rev. Bras. Educ., p.125-145, 2014.

NAVEED, M.A.; AMEEN, K. Information seeking anxiety among postgraduate students of university. J. Behavioural Scie., p.142-154. 2016 .

PALADINI, E.P. Gestão da qualidade no processo Belo Horizonte: a qualidade na produção de bens e serviços. Belo Horizonte: Fundação Cristiano Ottoni, 1995.

SElltiZ, C.; WRIGHTSMAN, L.; COOK, S. Métodos de pesquisa nas relações sociais. São Paulo: E.P.U., 1987.

SIANI, S.R.; CORREA, D.A.; LAS CASAS, A.L. Fenomenologia, método fenomenológico e pesquisa empírica Revista de Administraçãao da UNIMEP: o instigante universo da construção de conhecimento esquadrinhada na experiência de vida. Rev. Adm. UNIMEP, v.14, n.1, p.193-219, 2016.

SIMON, H.A. A behavioral model of rational choice. Quarterly J. Economics, p.99-118, 1955.

TAYLOR, J.W. The role of risk in consumer behavior. J. Marketing, p.54-60. 1974.

THALER, R. Toward a positive theory of consumer choice. $J$. Economic Behavior and Org., p.39-60, 1982.

TROY, I.; WERLE, R. Uncertainty and the market for patents. Max Planck Institute for the study of societies. 2008 Disponível em: <http://www.mpifg.de/pu/workpap/wp08-2.pdf $>$. Acesso em: 14 abr. 2019.

WIPO. World Intellectual Property Organization - Statistics for Researchers. Disponível em: <http://ipstats.wipo.int/ipstatv2/ index.htm> Acesso em: 15 abr. 2019.

ZEITHAML, V.A.; BERRY, L.L.; PARASURAMAN, A. A conceptual model of service quality and its implications for future research. J. Marketing, p.41-50. 1985. 